\title{
SCADA system for optimization of energy exchange with the BESS in a residential case
}

\author{
Roberto Faranda, Lorenzo Gozzi, Alessandro Bosisio, Kishore Akkala \\ Politecnico di Milano \\ Department of Electrical Engineering \\ Milan, Italy \\ roberto.faranda@polimi.it, lorenzo.gozzi@mail.polimi.it, alessandro.bosisio@polimi.it, nagavenkata.akkala@polimi.it
}

\begin{abstract}
The constant increase in the demand for electric energy, as well as the necessity to reduce the $\mathrm{CO}_{2}$ emissions into the atmosphere, imposes new challenges for energy management systems. In this regard to promote a sustainable energy generation, through the directives from Green Politics, countries provide incentives for renewable energy generation, which resulted in a rapid increase in the installation of $P V$ plants. Due to the volatile nature of the renewables and to manage the energy, it is becoming fundamental to install BESS (Battery Energy Storage System) both for residential and industrial energy customers. This paper presents a new way to use SCADA (Supervisory Control and Data Acquisition) system, which allows direct communication between the monitored system and a data server where the data is analysed for optimal design of the system. A mathematical model to optimize the size of the BESS, which minimises the energy exchange with the utility grid is introduced. A case study conducted on residential customer demonstrates that the proposed approach is a valuable tool for BESS design.
\end{abstract}

Keywords-BESS, SCADA, PV Plants, energy consumption, energy storage, load management, solar energy.

\section{INTRODUCTION}

With the development and installation of renewable energy sources, which are rapidly increasing [1], the necessity to improve the control of the grid and to transform it to a smart one [2] is becoming more fundamental. Indeed, big producers of electrical energy will not be so fundamental for Utility Grid and a big amount of electrical energy will be produced close to the consumption points. In the near future, every end-user will not only be a consumer but also could be a potential producer of the energy at the same time. The end-user transforms from "passive" to an "active" participant, creating a new class of customers [3].

In this context, Battery Energy Storage Systems (BESS) [4] are needed to exploit the reliance from the Utility Grid [5]. The BESS permits the residential prosumers to decide the best option for its energy consumption as well as equip the Utility Grid to have an additional tool to manage the load profile by reducing peak demand [6-7]. In order to reduce the expenditures on BESS installation, it is essential to precisely size the BESS. In this regard, the customer energy exchange with the utility grid [2] is fundamental in order to determine the accurate BESS size through analysis. Even though the new generation of meters allow the analysis of load energy profile, due to their evaluation of the medium datum [8-10] only for every 15 minutes pose limitations and makes the data unsuitable for sizing the BESS. Also, the current state of the art installation of a BESS is common only when an end-user has an excess of energy generation, however, sizing of the BESS in this case is estimated as an approximation. This leads to the necessity of acquiring data at a higher sampling rate. A communication system permits to acquire data from the field and send it to a central server, where this data is stored and analyzed for sizing the BESS. Thanks to the SCADA system [11-12], this necessity can be fulfilled. Thanks to an in-depth energy consumption analysis of the customer, it is possible to get interesting advantages, for example, a customer with a PV system without BESS, this analysis can help to get the right BESS size without oversizing it and avoiding extra-costs [2].

Considering the scenario in Italy, where the Gestore dei Servizi Energetici (GSE) reports the number of installations, the total installed capacity and the total generated energy of PV plants, it is can be verified that more than $91 \%$ of 732,053 PV plants have an installed capacity lower or equal to $20 \mathrm{~kW}$. These PV plants are mostly for residential use, [1] and even though their installed capacity is only $20 \%$ of $19.283 \mathrm{MW}$ (the total installed capacity), they are very significant for the Utility Grid because they are installed in LV network [14] and very close to the end-user.

Compared to the previous years the installation of new PV plants is reducing in number due to the reduction in the incentives from the governments [13] and [15]. However, the BESS are receiving increasing attention [1] and data from the market indicates a 71\% growth in BESS installations for 2017 with respect to 2016 [8] and [16]. The BESS market growth is due to interesting incentives it can provide and also to fulfil the needs of the end-user, who wants to self-consume their produced energy [14]. Majority of these installed BESS sizing is done on a rough basis, rather than with a detailed analysis on end-user load profile. Also, in this case, it is possible to decide the downsizing of contractual power from the Utility Grid with a cost reduction on the electricity bill or upgrading the entire system (BESS and/or PV) focusing on the desire independence from the network [5].

In this study, a new strategy for the management of residential end-user data through a SCADA system in order to perform analysis and provide accurate sizing of the BESS is taken up. Case studies are performed considering the scenarios of with and without an optimized PV, as reported in [17] and [18], for sizing the BESS.

The paper is organized as follows: in Section II the mathematical model is developed for optimizing the BESS 
size and the power exchange with the network. Section III presents a generic BESS model and its sizing. Section IV describes the SCADA system adopted for data gathering and analysis. In Section V a case study taken up to demonstrate that the proposed method is elaborated with the relevant hypothesis. The paper ends with a short conclusion and future work in Section VI.

\section{MODEL FORMULATION}

In this section, a mathematical model to find optimal BESS size is presented. The residential system considered for this model is shown in Fig. 1, which includes a Load, a PV plant, a BESS and the network.

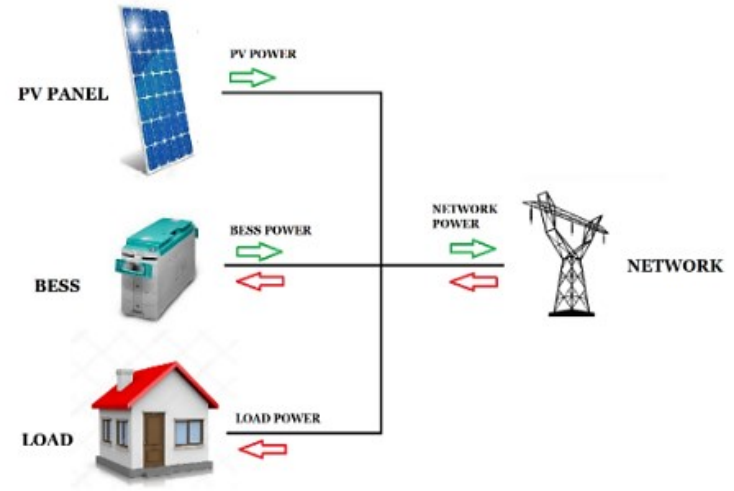

Fig. 1. System model

Considering a single residential end-user, the objective is to find the optimal BESS size to minimize the power exchange with the utility grid. The developed model takes the measured data of load consumption and PV production as inputs. On the other hand, BESS power, BESS energy, as well as power exchange with the utility grid are the unknown data.

The decision variables are as follows:

- P $_{\text {BATtery }}(\mathrm{k})$ : is the BESS power at time $\mathrm{k}$;

- $\mathrm{E}_{\text {BATTERY }}(\mathrm{k})$ : is the BESS state of charge at time $\mathrm{k}$;

- $\mathrm{P}_{\text {NETWORK }}(\mathrm{k})$ : is the utility grid power at time $\mathrm{k}$;

- $\varepsilon_{1}$ : is the relaxation variable related to power;

- $\varepsilon_{2}$ : is the relaxation variable related to energy.

The objective function to be minimized is equation (1):

$\mathrm{F}(\overline{\mathrm{x}})=\sum_{\mathrm{k}=0}^{\mathrm{N}} \mathrm{E}_{\text {BATTERY }}(\mathrm{k})^{2}+\mathrm{w}_{1} \cdot \varepsilon_{1}+\mathrm{w}_{2} \cdot \varepsilon_{2}$

Where $\mathrm{N}$ is the total number of time steps; $\mathrm{w}_{1}$ and $\mathrm{w}_{2}$ are the weights assigned to the relaxation variables $\left(10^{3}\right.$ order $)$.

The objective function is subjected to the following constraints:

$$
\begin{aligned}
& \mathrm{P}_{\text {BATtery,MaXdis }} \leq \mathrm{P}_{\text {BATtery }} \leq \mathrm{P}_{\text {BATtery,MaXCH }} \\
& \mathrm{P}_{\text {NETWORK,MAXABS }} \leq \mathrm{P}_{\text {NETWORK }} \leq \mathrm{P}_{\text {NETWORK,MAXSUP }}
\end{aligned}
$$

Where $P_{\text {BATtery,MaXdis }}$ and PBATtery,MAXCh $_{\text {are the }}$ maximum power that the BESS can discharge or charge and $\mathrm{P}_{\text {NETWORK,MAXABS }}$ and $\mathrm{P}_{\text {NETWORK,MAXsUP }}$ are the minimum and maximum power that the utility grid can exchange with the domestic user power system. is:

The power balance equation to be fulfilled at any time $\mathrm{k}$

$$
\mathrm{P}_{\mathrm{PV}}(\mathrm{k})-\mathrm{P}_{\mathrm{BATTERY}}(\mathrm{k})+\mathrm{P}_{\mathrm{NETWORK}}(\mathrm{k})-\mathrm{P}_{\mathrm{LOAD}}(\mathrm{k})=0
$$

In order to speed up convergence of the solution, a relaxation to equation (4) is applied. Thus, a new variable $\varepsilon_{1}$ is defined which transforms the equation (4) into a system of two equations (5) and (6):

$$
\begin{aligned}
& \mathrm{P}_{\mathrm{PV}}(\mathrm{k})-\mathrm{P}_{\text {BATTERY }}(\mathrm{k})+\mathrm{P}_{\text {NETWORK }}(\mathrm{k})-\mathrm{P}_{\mathrm{LOAD}}(\mathrm{k}) \leq \varepsilon_{1} \\
& -\left(\mathrm{P}_{\mathrm{PV}}(\mathrm{k})-\mathrm{P}_{\text {BATTERY }}(\mathrm{k})+\mathrm{P}_{\text {NETWORK }}(\mathrm{k})-\mathrm{P}_{\mathrm{LOAD}}(\mathrm{k})\right) \leq \varepsilon_{1}
\end{aligned}
$$

The battery state of energy (EBATERY) depends on the power that the battery had injected/absorbed by the system in the previous and current time frame, as shown in Fig. 2.

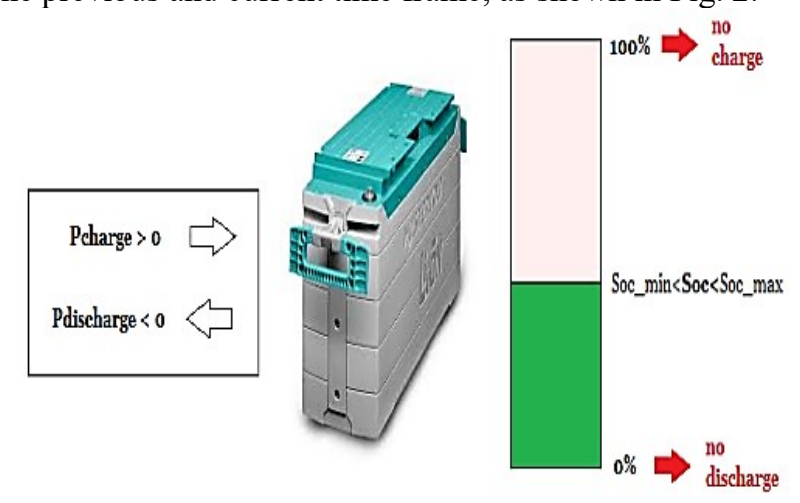

Fig. 2. Battery state of charge

The energy balance is as follows:

$\mathrm{E}_{\text {BATTERY }}(\mathrm{k}+1)-\mathrm{E}_{\text {BATTERY }}(\mathrm{k})-\mathrm{P}_{\text {BATTERY }}(\mathrm{k}) \cdot \mathrm{T}=0$

Where $\mathrm{T}$ is the time step considered. Similar to equation (4), it is possible to obtain a relaxation to equation (7) adding new variable $\varepsilon_{2}$. The equation (7) becomes:

$$
\begin{array}{r}
\mathrm{E}_{\text {BATTERY }}(\mathrm{k}+1)-\mathrm{E}_{\text {BATTERY }}(\mathrm{k})-\mathrm{P}_{\text {BATTERY }}(\mathrm{k}) \cdot \mathrm{T} \leq \varepsilon_{2} \\
-\left(\mathrm{E}_{\text {BATTERY }}(\mathrm{k}+1)-\mathrm{E}_{\text {BATTERY }}(\mathrm{k})-\mathrm{P}_{\text {BATTERY }}(\mathrm{k}) \cdot \mathrm{T}\right) \leq \varepsilon_{2}
\end{array}
$$

Moreover, charging/discharging efficiencies must be considered.

Thus, equation (7) changes either to equation (10) or to equation (11) for discharging and charging respectively:

$$
\begin{aligned}
& \mathrm{E}_{\text {BATTERY }}(\mathrm{k}+1)-\mathrm{E}_{\text {BATTERY }}(\mathrm{k})-\eta^{-} \cdot \mathrm{P}_{\text {BATTERY,DIS }} \cdot \mathrm{T}=0 \\
& \mathrm{E}_{\text {BATTERY }}(\mathrm{k}+1)-\mathrm{E}_{\text {BATTERY }}(\mathrm{k})-\eta^{+} \cdot \mathrm{P}_{\text {BATTERY,CH }} \cdot \mathrm{T}=0
\end{aligned}
$$

Where:

$$
-\mathrm{P}_{\text {BATTERY,MAX }} \leq \mathrm{P}_{\text {BATTERY,DIS }} \leq 0
$$

and:

$$
0 \leq \mathrm{P}_{\text {BATTERY,CH }} \leq \mathrm{P}_{\text {BATTERY,MAX }}
$$

The output of this model are the optimized values of

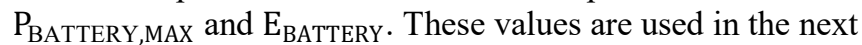
section for sizing the BESS.

\section{BESS MODELLING}

To correctly represent a BESS, several aspects need to be considered (chemical, electrical and mechanical components) at the same time. Therefore, a multi-physics approach must be considered to correctly size the BESS (from power and energy point of view). A parameter that can be used to correctly represent the size of a BESS can be the SoC (State of Charge).

There are different approaches that can be followed to evaluate the BESS SoC:

- electrochemical, in which SoC is related to the concentrations of reactants, and it consists of a 
system of differential equations in time and space domain;

- electrical, where batteries can be represented by equivalent electrical circuits composed by circuital elements and, thanks to the experimental evaluation of several operating conditions, the $\mathrm{SoC}$ can be estimated;

- analytical, that permits to evaluate the SoC through energy balance and so, its value is equal to State of Energy (SoE).

In the following, the analytical approach is exploited.

To correctly model the SoC of a BESS, it is necessary to measure the discrete value of the power and it important to know and estimate the efficiency of the BESS and the efficiency of the AC/DC converter. Therefore, it is possible to evaluate the total efficiency of the BESS by including both efficiencies in a unique parameter. The total efficiency also depends on the charging/discharging condition (C-rate).

In particular, the charging efficiency $\eta^{+}$can be considered equal to the discharging efficiency $\eta^{-}$for the same input power of charging or discharging, but considering that the available power, $\mathrm{P}_{\mathrm{m}}$, is measured to the network side, the $\eta^{+}\left(P_{m}\right)$ and $\eta^{-}\left(P_{m}\right)$ functions are different.

Therefore, to evaluate the real BESS power (Power) of charging or discharging it is necessary to use the corresponding equation (14) when the BESS is in charging or in discharging mode.

Power $\left\{\begin{array}{c}P_{\text {charging }}=\eta^{+}\left(\mathrm{P}_{\mathrm{m}}\right) \cdot \mathrm{P}_{\mathrm{m}} \\ P_{\text {discharging }}=\frac{1}{\eta^{-}\left(\mathrm{P}_{\mathrm{m}}\right)} \cdot \mathrm{P}_{\mathrm{m}}\end{array}\right.$

Then the Power can be integrated to find the charged or discharged energy, and this value is compared continuously with the initial SoC of the BESS.

Indeed, the Total Energy Stored (TES), equation (15), can be evaluated by integrating the input power to find the charging/discharging energy and adding it to the initial SoE (at $\mathrm{t}=0$ ).

TES $=\alpha($ Power $) \cdot \int$ Power $d t+\operatorname{SoC}(t=0)$

If TES is higher or lower than the maximum or minimum SoC, the BESS is totally charged or discharged. Hence, in the model, the BESS needs to represent this case in order not to provide or absorb power to/from the Utility Grid. To take this consideration into the BESS model, the coefficient $\alpha$ is introduced and its value is set equal to zero when this case arises.

Indeed, when the TES is inside the previous range, the BESS could provide or extract power to/from the network. So, the coefficient $\alpha$ is set equal to one.

The ratio between TES and the Nominal Capacity of the BESS gives the percentage of SoC [\%] of the BESS in each iteration step of the simulation.

SoC $[\%]=\frac{\text { TES }[\mathrm{Wh}]}{\text { Nominal Capacity }[\mathrm{Wh}]}$

Another very important parameter is the total number of the depth of charging and discharging cycles of the BESS because this parameter influences the battery state of health, and this can influence the result due to the high number of charging and discharging cycles during the normal daily operation. To estimate whether the BESS is respectively in charging or discharging phase, it is necessary to know the value of the power, if it is higher or lower than zero.

The number of charging or discharging cycles is expressed as the ratio between the charging or discharging energy evaluated as $\int$ Power $\cdot \mathrm{dt}$ and the BESS Nominal Capacity.

$\mathrm{n}_{\mathrm{t}}=\frac{\mid \int \text { Power } \cdot \mathrm{dt} \mid}{\text { Nominal Capacity }}$

So, the total number of cycles can be calculated as reported in equation (18):

$\mathrm{TC}=\frac{n_{\text {Charging Cycles }}+n_{\text {Discharging Cycles }}}{2}$

Through this analysis, an optimal sizing of the BESS can be evaluated.

\section{SCADA SYSTEM}

In order to develop a management system for the data collection, transmission and analysis, a SCADA system is realized. The system is composed of a smart device capable to meter the value of voltage and current at the same time and send them to the main data server located in our laboratory, serves as the infrastructure.

In the market, it is possible to find different smart devices for energy measurement, but only a few among them can be used to apply the model presented in the previous section. A smart device that can be utilized in this study must have the fundamental characteristics as described below:

- time, voltage and current detectors, with a sampling rate for every one second is desired, to provide a detailed load curve, can be called as smart plug;

- a secure and reliable communication channel to connect between the data server and the measurement device in order to collect the measured data and perform the analysis;

- a memory card, that permits to store the data when the connection is busy, in order to avoid data loss.

Another very import characteristic of the device is the need of easy installation in order to facilitate the huge diffusion of the proposed methodology.

The SCADA system realized for this study consists of a smart plug installation at the desired residential end-user. The data server hosted over a website of the Politecnico di Milano serves the purpose of the data storage and analysis. The interaction between the data server and the smart plug is done through a request by the server with a POST method in JSON is sent to the smart plug (using PHP language) for data acquisition. Due to the constraints of the informatics system of the University, it is not possible to receive the data every second, so the frequency of the request is reduced to one request per hour. For this reason, a memory that historicizes the data inside the board is essential; however, even if there could be the possibility to transmit every second, the memory can save the data in the event of loss of connection to the data server. In order to permit the program to start the analysis, the end-user's characterization of the system is necessary.

Moreover, through the website, it is possible to specify the type of analysis desired if referred to an implementation of the plant (installation of PV, BESS or both) or only to check energy consumption to modify the contract with the network [6]. When data arrives at the server, they are saved on MySQL database, which is then downloaded to the host PC and processed by the algorithm described in the previous section, the output of the analysis is uploaded to the client's personal 
page on the website.

\section{CASE STUDY AND RESULTS}

The case study is taken up for a residential end-user by measuring and storing the data of current and voltage for two weeks, in order to find the optimal size of the BESS needed under different cases. For the preliminary analysis of the algorithm developed, the data are collected on-field and are sent to a host PC using RS232, for the sizing of the BESS.

To measure the voltage and current values, an electronic board (smart plug) is developed which is shown in Fig. 3. The electronic measurement unit needs an external power supply to work, and it consists of internal circuits for measurement units (one each for voltage and current measurement) and a processing unit (in this case a microcontroller) for storing data locally and establishing communication. This device is placed in series to the end-user load.

The voltage is measured with a voltage transformer, stepped down to a value readable by the microcontroller. Similarly, the current is measured using a toroidal sensor and passed to the microcontroller. The microcontroller processes the measurements and sends them to the host PC using RS232 serial communication. The data is transmitted to a PC as text files and later exported to Excel in order to create appropriate elaborations.

Considering the huge amount of data, and that we are only interested in a preliminary evaluation of the performance of the proposed method, the measured voltage and current data is used to calculate the power and is averaged for every $15 \mathrm{~s}$. This medium value of power is used in order to obtain the trend of the end-user load for a span of two weeks.

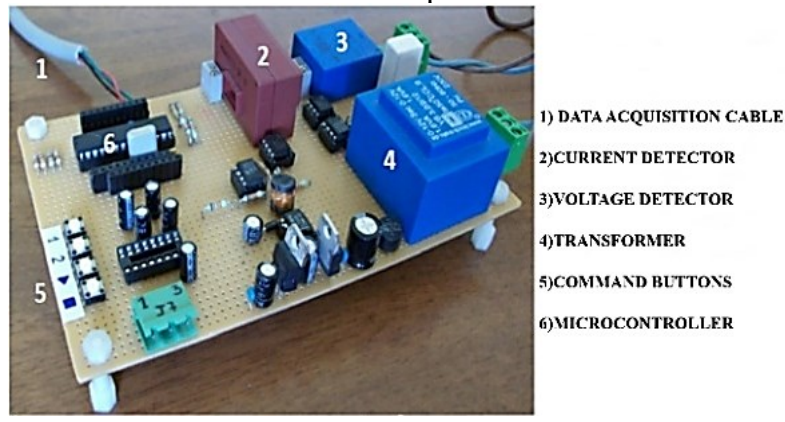

Fig. 3. Electronic Measurement Board (Smart Plug)

The end-user absorbed power, reported in Fig. 4 and Fig. 5 , is characterized by small data set with high variability. It is possible to observe that during the night, the consumptions are very similar, but in the case of the day, the consumptions are varying over the time span. The limit of the contractual power to the Utility Grid (max power exchange permitted) is set to different values depending on the desired independence the end-user wants to obtain. For this analysis, the contractual power limit has been imposed to values equal to $1 \mathrm{~kW}, 1.5 \mathrm{~kW}$ and $3 \mathrm{~kW}$

As a high number of charge and discharge cycles are expected, in this study a BESS with a very long-life cycle and able to support this technical effort is used. So, a $\mathrm{LiFePO}_{4}$ (lithium-iron-phosphate) BESS has been chosen, as its technical characteristics permit to have a very good state of health [16]. It is characterized by a percentage of discharge up to $100 \%$ with a daily average recommended around $80 \%$. The efficiency of the BESS in function of C-rate is shown in Fig.
6. In order to simplify the simulation process and considering that this is a preliminary study to understand the ability of the proposed model to optimize a BESS, in this work the charging/discharging efficiencies are considered as constant values.

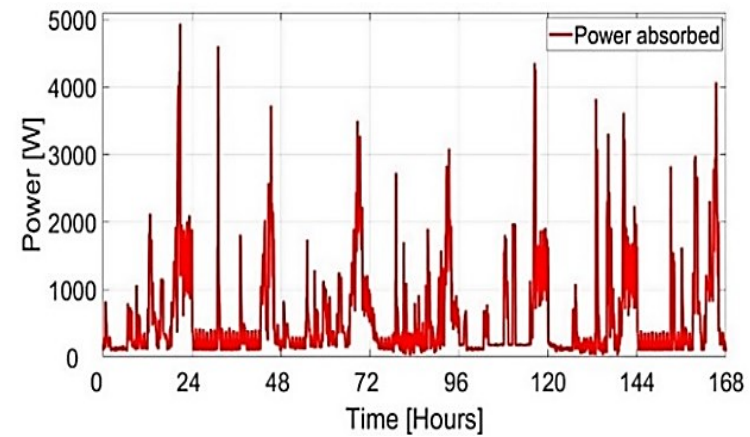

Fig. 4. Customers load profile for first week

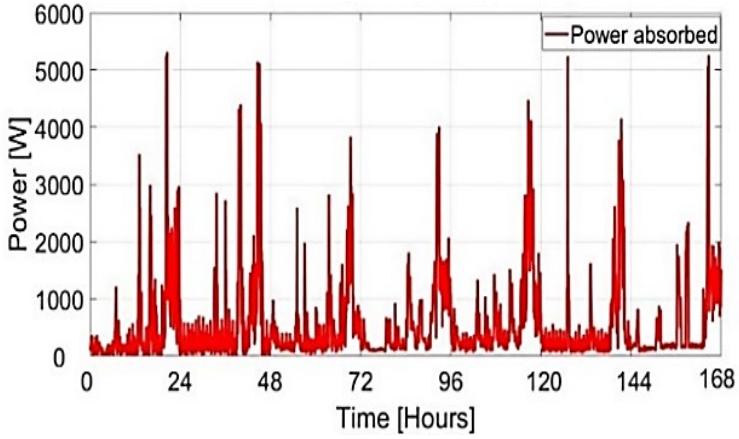

Fig. 5. Customers load profile for second week

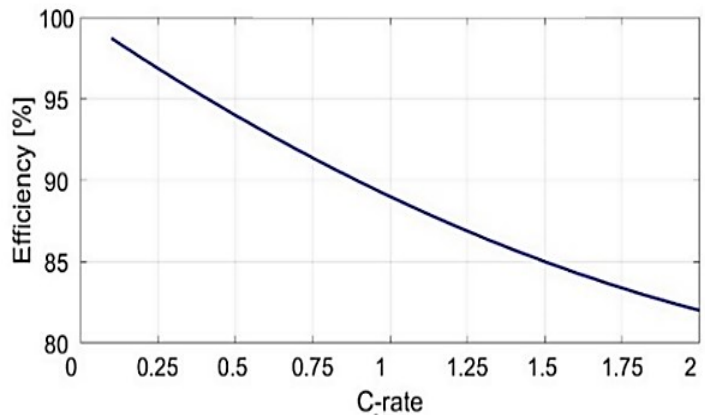

Fig. $6 \mathrm{LiFePO}_{4}$ BESS efficiency

Now that all the BESS characteristics and load power are exploited, it is possible to start the optimization process. Emphasizing that the main purpose of BESS is to reduce the limit of the contractual power from the Utility Grid and to manage the generated power of the end-user, in the following analysis, the BESS has been sized for different working conditions. The Load, the BESS and the network under analysis are shown in Fig. 7.

In order to evaluate the load power in the presence of a PV plant, the PV production profile has been simulated and added to the absorbed load power reported in Fig. 4 and Fig. 5. In order to get a real load profile, the PV production has been simulated considering real weather conditions of the two weeks under analysis. In this study, three test cases are considered: the first one without PV generation, the second one with a PV generation of $1.5 \mathrm{~kW}$ and the last one with a $\mathrm{PV}$ generation of $3 \mathrm{~kW}$.

In all the test cases, the SoC of BESS is considered empty 
at the beginning and at the end of the simulations. The simulations are carried out in all the cases for illustrative purposes only.

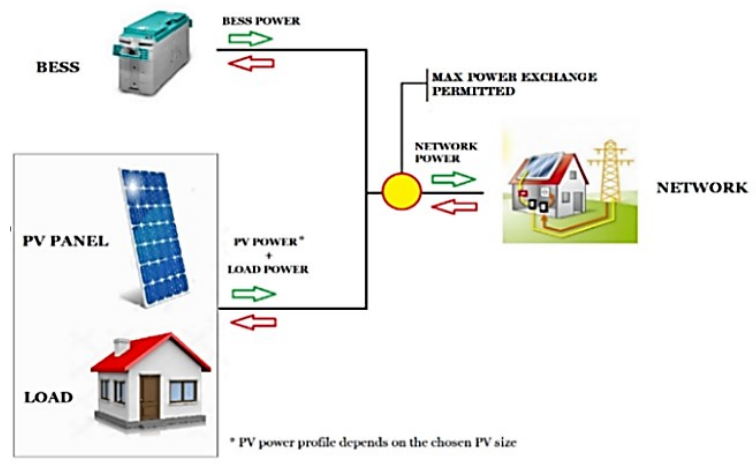

Fig. 7. Single user under analysis

\section{A. Case A-Load without PV}

In the first case, there is no PV generation and the contractual power to the Utility Grid is limited to $1 \mathrm{~kW}$, $1.5 \mathrm{~kW}$ and $3 \mathrm{~kW}$.

The representation of the load profile that exceeds the imposed limits on contractual power is shown in Fig. 8. It can be observed from Fig. 8 that the power peaks are spread apart when the contractual power limit is $3 \mathrm{~kW}$, but if the contractual power limit is reduced, the occurrence of peaks above the power limit are increased.

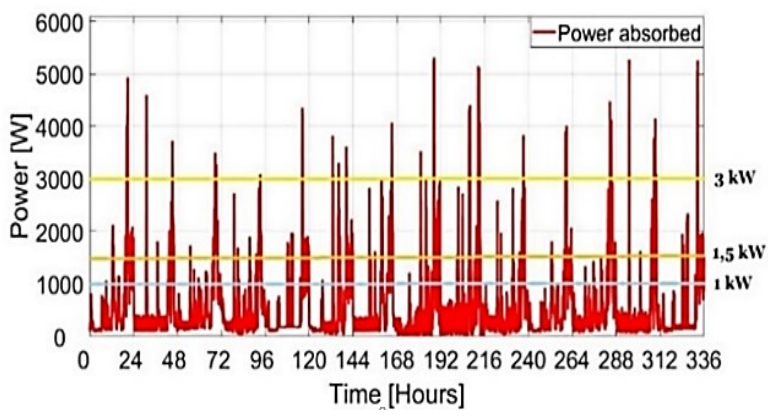

Fig. 8. Case A: Load profile with no PV

Therefore, it is necessary to consider that, lowering the contractual power limits from $3 \mathrm{~kW}$ to $1 \mathrm{~kW}$, the normal load during the day time exceeds the limits of the contractual power for a large time periods, demanding an exponential increase in the size of the BESS. In this case, the lower limit is always equal to zero because PV production is not present and hence power injection into the Utility Grid is always null.

\section{B. Case B - Load with $P V=1.5 \mathrm{~kW}$}

In the second case, to evaluate the effect of PV generation on the sizing of the BESS, a $1.5 \mathrm{~kW}$ of PV generation is added to the load.

As reported in Fig. 9, adding the PV production to the load profile reduces the number of peaks in load consumption. Obviously, when PV generation does not coincide with load peaks, they are equal to the previous case, hence the BESS size will be necessarily the same as in the previous case. In this case, due to power injection into the Utility Grid from the $\mathrm{PV}$, a lower negative limit is considered. It could be observed that the lower limit imposed cannot be reached with the PV production for these two weeks, for the three limits, $-1 \mathrm{~kW},-1.5 \mathrm{~kW}$ and $-3 \mathrm{~kW}$. Hence, the BESS size is expected to be close to the previous case.

An interesting case can be to analyze the system for a lower limit imposed to zero. In this case, no energy can be injected in the network, but it must be all self-consumed by the load, it is necessary to store all the surplus energy into the BESS, and consequently, this will increase the BESS dimension with respect to the injection case with the same upper limit.

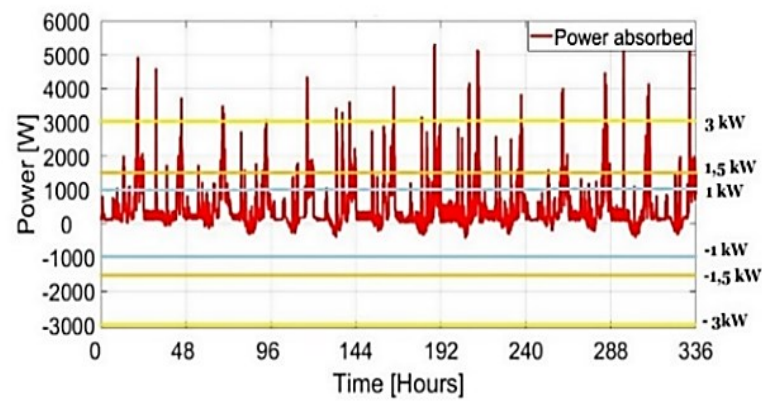

Fig. 9. Case B: Load profile with PV of $1500 \mathrm{Wp}$

\section{Case C-Load with $P V=3.0 \mathrm{~kW}$}

In the third case, a PV generation with a dimension of $3 \mathrm{~kW}$ is added. Examining the load profile in Fig. 10, it is possible to understand that in this case the lower limit is not reached and the obtained results about the BESS size are similar to Case B with the negative limits.

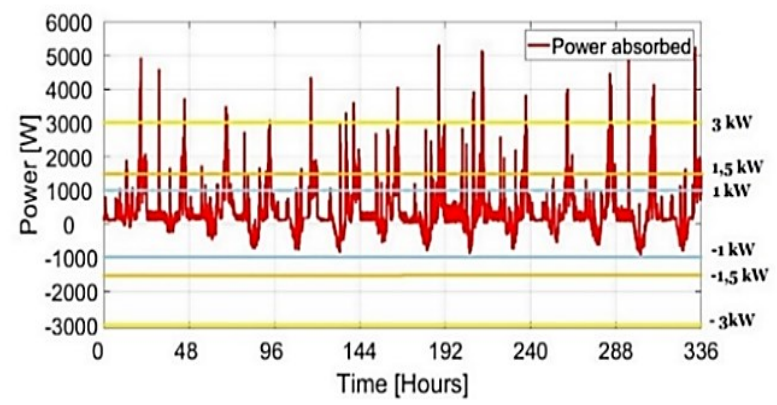

Fig. 10 Case C: Load profile with PV of $3000 \mathrm{Wp}$

It could be immediately noticed how the lower limit imposed cannot be reached with this photovoltaic production profile in any of the three possible cases of contractual power limits. For this reason, the size of the BESS is expected to be very similar to the case without generation, with only a minor difference in size.

If the lower limit is set to zero, the behavior of the system is equal to the Case B but with a higher PV energy generation that needs to be stored and consequently requires higher BESS size.

\section{Results comparison}

The Table I summarizes different cases in which the contractual absorbed power limit equal to $3 \mathrm{~kW}, 1.5 \mathrm{~kW}$ and $1 \mathrm{~kW}$, with injection power limits of $-3 \mathrm{~kW},-1.5 \mathrm{~kW},-1 \mathrm{~kW}$ or zero taken as lower limits. The dimension of the BESS in both these cases leads to an increase of the BESS power by $60 \%$ if the contractual power is reduced from $3 \mathrm{~kW}$ to $1.5 \mathrm{~kW}$ and an increase of an additional $11 \%$ from $1.5 \mathrm{~kW}$ to $1 \mathrm{~kW}$. This result is caused by the necessity to satisfy peak loads 
through the BESS, which are normally supplied by the network.

The energy size is strictly correlated with the dimension of the PV plant for the largest power limit. In fact, with a limit of $3 \mathrm{~kW}$, BESS size is $304 \mathrm{Wh}$ in Case B and $1059 \mathrm{Wh}$ in Case C. Comparing both in Case C, BESS size is three times larger than to the Case B. When we reduce the contractual power limit, the increment of BESS energy size is correlated more to the power limit than to the PV dimension, because the load peaks are higher in number. This result could be different if it is considered to have a higher PV generation, which is season-dependent. In this study, the PV power peak (Wp) reached is around $500 \mathrm{~W}$, instead of a possible $1500 \mathrm{~W}$ of installed capacity for Case $\mathrm{B}$, and the same consideration is possible for Case C.

\section{TABLE I. BESS OPTIMIZATION RESULTS}

\begin{tabular}{|c|c|c|c|c|}
\hline \multicolumn{2}{|c|}{$\begin{array}{l}\text { Network Exchange } \\
\text { Power Bounds }\end{array}$} & \multicolumn{3}{|c|}{ BESS energy size and (power size) } \\
\hline $\begin{array}{l}\text { Lower } \\
\text { limit }\end{array}$ & $\begin{array}{l}\text { Upper } \\
\text { limit }\end{array}$ & $\begin{array}{c}\text { Case A } \\
\mathrm{PV}=0 \mathrm{Wp}\end{array}$ & $\begin{array}{c}\text { Case B } \\
\mathrm{PV}=1500 \mathrm{Wp}\end{array}$ & $\begin{array}{c}\text { Case C } \\
\mathrm{PV}=3000 \mathrm{Wp}\end{array}$ \\
\hline $0 \mathrm{~kW}$ & $3 \mathrm{~kW}$ & $\begin{array}{c}214 \mathrm{Wh} \\
(2,417 \mathrm{~W})\end{array}$ & $\begin{array}{c}304 \mathrm{Wh} \\
(2,417 \mathrm{~W})\end{array}$ & $\begin{array}{l}1,059 \mathrm{Wh} \\
(2,417 \mathrm{~W})\end{array}$ \\
\hline $0 \mathrm{~kW}$ & $1.5 \mathrm{~kW}$ & $\begin{array}{l}1,137 \mathrm{Wh} \\
(3,874 \mathrm{~W})\end{array}$ & $\begin{array}{l}1,126 \mathrm{Wh} \\
(3,874 \mathrm{~W})\end{array}$ & $\begin{array}{l}1,439 \mathrm{Wh} \\
(3,874 \mathrm{~W})\end{array}$ \\
\hline $0 \mathrm{~kW}$ & $1 \mathrm{~kW}$ & $\begin{array}{l}2,259 \mathrm{Wh} \\
(4,361 \mathrm{~W})\end{array}$ & $\begin{array}{l}2,237 \mathrm{Wh} \\
(4,361 \mathrm{~W})\end{array}$ & $\begin{array}{l}2,324 \mathrm{Wh} \\
(4,361 \mathrm{~W})\end{array}$ \\
\hline$-3 \mathrm{~kW}$ & $3 \mathrm{~kW}$ & l & $\begin{array}{c}207 \mathrm{Wh} \\
(2,417 \mathrm{~W})\end{array}$ & $\begin{array}{l}204 \mathrm{Wh} \\
(2,417 \mathrm{~W})\end{array}$ \\
\hline$-1.5 \mathrm{~kW}$ & $1.5 \mathrm{~kW}$ & / & $\begin{array}{l}1,126 \mathrm{Wh} \\
(3,874 \mathrm{~W})\end{array}$ & $\begin{array}{l}1,121 \mathrm{Wh} \\
(3,874 \mathrm{~W})\end{array}$ \\
\hline$-1 \mathrm{~kW}$ & $1 \mathrm{~kW}$ & l & $\begin{array}{l}2,237 \mathrm{Wh} \\
(4,361 \mathrm{~W})\end{array}$ & $\begin{array}{l}2,227 \mathrm{Wh} \\
(4,361 \mathrm{~W})\end{array}$ \\
\hline
\end{tabular}

If the energy exchange with the Utility is possible, the sizing in terms of energy for the BESS in Case C is reduced, with an increase of PV dimension. This can be seen from Case $\mathrm{B}$ to Case $\mathrm{C}$ with the lower network limit of $-3 \mathrm{~kW}$ and upper limit of $3 \mathrm{~kW}$, which is equal to $207 \mathrm{Wh}$ in the Case B and $204 \mathrm{Wh}$ in Case C, corresponding to a reduction of about $1 \%$. This analysis, having only done for a demonstrative purpose, has measured the data for just two weeks. However, the result could be of slight difference for data measured over a larger time span, particularly when the PV production is optimal.

\section{CONCLUSION}

The proposed paper describes a new methodology to size a BESS for an end-user. Starting from real active power measures of the load, the proposed methodology permits to evaluate optimized values in order to accurately size the BESS and the contractual power limit with the Utility Grid. To approach to this solution, an optimization algorithm is proposed. The infrastructure for the SCADA system developed is described, which permits the metering of data and the direct transmission to the data server for the analysis. Through the case study performed, the applicability of the proposed method of analysis is demonstrated, avoiding an overestimation of the contractual power or re-setting it when the BESS has been already installed.

\section{REFERENCES}

[1] IRENA, Electricity storage and renewables: Costs and markets to 2030, no. October. 2017

[2] J. T. Liao, Y. S. Chuang, H. T. Yang, and M. S. Tsai, BESS-Sizing Optimization for Solar PV System Integration in Distribution Grid, IFAC-PapersOnLine, vol. 51, no. 28 , pp. 85-90, 2018
[3] R. Zafar, A. Mahmood, S. Razzaq, W. Ali, U. Naeem, K. Shehzad, Prosumer based energy management and sharing in smart grid, Renew. Sustain. Energy Rev., vol. 82, no. August 2016, pp. 1675-1684, 2018

[4] X. Li, D. Hui, X. Lai, Battery energy storage station (BESS)-based smoothing control of photovoltaic (PV) and wind power generation fluctuations, IEEE Trans. Sustain. Energy, vol. 4, no. 2, pp. 464-473, 2013

[5] R. L. Fares, M. E. Webber, Reduce Reliance on the Utility, Nat. Energy, vol. 2, no. January, 2017

[6] A. Arcos-Vargas, D. Lugo, F. Núñez, Residential peak electricity management. A storage and control systems application taking advantages of smart meters, Int. J. Electr. Power Energy Syst., vol. 102, no. April, pp. 110-121, 2018

[7] A. I. Nousdilis, G. C. Christoforidis, G. K. Papagiannis, Active power management in low voltage networks with high photovoltaics penetration based on prosumers' self-consumption, Appl. Energy, vol. 229, no. August 2018, pp. 614-624, 2018

[8] J. Torriti, People or machines? Assessing the impacts of smart meters and load controllers in Italian office spaces, Energy Sustain. Dev., vol. 20, no. 1, pp. 86-91, 2014

[9] S. D’Oca, S. P. Corgnati, T. Buso, Smart meters and energy savings in Italy: Determining the effectiveness of persuasive communication in dwellings, Energy Res. Soc. Sci., vol. 3, no. C, pp. 131-142, 2014

[10] S. S. S. R. Depuru, L. Wang, V. Devabhaktuni, Smart meters for power grid: Challenges, issues, advantages and status, Renew. Sustain. Energy Rev., vol. 15, no. 6, pp. 2736-2742, 2011

[11] P.-C. Pasc, C.-D. Dumitru, SCADA System for Solar MPPT Controller Monitoring, Procedia Technol., vol. 22, pp. 803-807, 2016

[12] J. Figueiredo, J. Sá Da Costa, A SCADA system for energy management in intelligent buildings, Energy Build., vol. 49, pp. 85-98, 2012

[13] S. Clò, A. Cataldi, P. Zoppoli, The merit-order effect in the Italian power market: The impact of solar and wind generation on national wholesale electricity prices, Energy Policy, vol. 77, pp. 79-88, 2015

[14] H. Hafezi, G. D’Antona, A. Dedè, D. Della Giustina, R. Faranda, G. Massa, Power Quality Conditioning in LV Distribution Networks: Results by Field Demonstration, in IEEE Transactions on Smart Grid, vol. 8, no. 1, pp. 418-427, Jan. 2017

[15] M. Antonelli, U. Desideri, The doping effect of Italian feed-in tariffs on the PV market, Energy Policy, vol. 67, pp. 583-594, 2014

[16] Saikrishna Ooud J.S., Tunga S., Sultana Q., Bindu S., Li-ion based Optimally Sized Grid Interfaced Rooftop $P V$ System, 3rd 1nternational Conference on Electrical Energy Systems, Manipal Institute of Technology, Manipal, India, 2016

[17] R. Faranda, H. Hafezi, S. Leva, M. Mussetta, E. Ogliari, The optimum PV plant for a given solar dc/ac converter, Energies, vol. 8, no. 6, pp. 4853-4870, May 2015

[18] R. Faranda, H. Hafezi, S. Leva, M. Mussetta, E. Ogliari Energy production estimation for suitable PV Planning, proceedings of the 22th International Conference SPEEDAM, Ischia, Italy, 18-20 June 2014. 